\title{
Limited benefit of hepatitis B immunoglobulin prophylaxis in children of hepatitis $B$ e antigen-negative mothers
}

Le Ye $\underline{L e e}^{1,2}$, MMed, MRCPCH, Marion M $\underline{A w}^{1,2}$, MMed, FRCPCH, Sharon Saw ${ }^{3}$, MSc, PhD, Mary $\underline{\operatorname{Rauff}}^{4}$, FRCOG, MMed, Pearl YS Tong 4 , MRCOG, MMed, Guan Huei Lee ${ }^{5,6}$, MRCP, PhD

INTRODUCTION In 2006, Singapore adopted the universal hepatitis B immunoglobulin (HBIg) policy. Since then, all infants of hepatitis B surface antigen ( $\mathrm{HBsAg}$ )-positive mothers receive $\mathrm{HBlg}$, irrespective of maternal hepatitis $\mathrm{B}$ e antigen ( $\mathrm{HBeAg}$ ) status. However, the benefits of HBlg for infants of HBeAg-negative mothers are unclear. We compared the vertical transmission rates among children of $\mathrm{HBeAg-negative} \mathrm{mothers} \mathrm{who} \mathrm{were} \mathrm{given} \mathrm{HBIg}$ versus a retrospective cohort who were not given HBIg, to determine its protective effect.

METHODS This observational study involved pregnant HBsAg-positive women seen at National University Hospital, Singapore, between June 2009 and December 2013. If the infants of these mothers completed the recommended vaccination schedule, they were recruited into the study, along with their older siblings. Serological testing for the children was performed three months after completion of the last dose of vaccine, and hepatitis B virus (HBV) surface gene sequencing was carried out if HBV DNA was detected.

RESULTS A total of 111 infants and 47 siblings were recruited. 2 (1.5\%) children were found to have vertical transmission despite receiving $\mathrm{HBIg}$, while no incidences of vertical transmission were found among the historical controls who did not receive HBIg $(p=1.00)$.

CONCLUSION The overall effectiveness of the hepatitis B vaccination programme for children of HBsAg-positive mothers was high, regardless of HBIg administration. The addition of HBIg did not appear to confer additional benefits, in terms of vertical transmission rate, among infants born to HBeAg-negative mothers.

Keywords: hepatitis B chronic carrier mothers, hepatitis B surface gene mutations, vertical transmission

\section{INTRODUCTION}

In Asia, chronic hepatitis B infection is usually acquired through vertical transmission from a chronic hepatitis B carrier mother to her newborn during the birth process. A person with chronic hepatitis B infection can be classified as either hepatitis B e antigen (HBeAg)-positive or HBeAg-negative; the former is usually accompanied by high viral load and high infectivity, while the latter is usually associated with low/negative viral load and low infectivity. In an attempt to minimise such vertical transmissions, in 2006, the World Health Organization (WHO) suggested that early vaccination against hepatitis B be administered to infants of chronic hepatitis B carrier mothers. ${ }^{(1)}$ However, the United States Centers for Disease Control and Prevention recommended greater precaution and advocated the administration of hepatitis $B$ immunoglobulin ( $\mathrm{HBIg}$ ) to these infants in addition to the hepatitis B vaccine. ${ }^{(2)}$

Prior studies conducted in Singapore in the 1990s showed that babies from HBeAg-negative carrier mothers were not at an increased risk of perinatal infection if they received the hepatitis $B$ vaccination within 24 hours of birth. ${ }^{(3,4)}$ Thus, until October 2006, Singapore's vaccination guideline for children of HBeAgnegative mothers included routine active hepatitis $B$ vaccination only, while those of $\mathrm{HBeAg}$-positive mothers received $\mathrm{HBIg}$ in addition to the hepatitis B vaccine. In November 2006, Singapore's vaccination guideline was changed to include universal prophylaxis, with both the hepatitis B vaccine and HBIg given at birth to infants of hepatitis B surface antigen (HBsAg)-positive mothers, irrespective of maternal HBeAg status. No formal review has been performed locally to determine if this change in the prophylaxis policy is effective or justified. Thus, the present study aimed to examine the vertical transmission rate among the cohort of children of $\mathrm{HBeAg}$-negative mothers who received $\mathrm{HBIg}$, and compare that rate with sibling controls who did not receive $\mathrm{HBIg}$, so as to determine the benefit of the addition of HBIg as universal prophylaxis.

\section{METHODS}

The present study was part of a larger cohort study that aimed to identify the factors related to vertical transmission. All pregnant women who were $\mathrm{HBsAg-positive} \mathrm{but} \mathrm{HBeAg-negative} \mathrm{and}$ attended National University Hospital, Singapore, from 1 June 2009 to 31 December 2013 were prospectively invited to participate in the present study. Informed consent was obtained to include infants of their current pregnancy (who would receive $\mathrm{HBIg}$ ) and the children born to them prior to the study (the majority 
of whom would not have received $\mathrm{HBI}$ ). The study protocol was approved by the National Healthcare Group Domain Specific Review Board.

The mothers had to be HBsAg-positive and HBeAg-negative in all their pregnancies for their children to be included in the present study. In addition, only infants who had received three doses of hepatitis B vaccine in Singapore were eligible for inclusion. Infants whose mothers had concurrent hepatitis $\mathrm{C}$ virus (HCV) or human immunodeficiency virus (HIV) infection were excluded, as these conditions are known to affect vaccine response.

All mothers had their hepatitis B viral load measured using real-time polymerase chain reaction ( $\mathrm{PPCR}$ ) that was performed in the Molecular Diagnostic Lab of National University Hospital, Singapore. The mothers were tested during their last trimester, close to their delivery time. Hepatitis B virus (HBV) DNA was measured using qPCR assay (artus ${ }^{\circledR}$ HBV PCR Kit; QIAGEN $\mathrm{GmbH}$, Hilden, Germany). The lowest detection limit for HBV DNA using these kits is $13.5 \mathrm{IU} / \mathrm{mL}$ of blood. HBsAg, hepatitis B surface antibodies (anti-HBs), hepatitis B core antibodies, $\mathrm{HCV}$ antibodies and HIV antigen antibodies were measured using diagnostic assays (Architect Diagnostic Assays; Abbott Laboratories Pte Ltd, Singapore).

All infants were administered three doses of hepatitis B vaccine (Engerix-B; GlaxoSmithKline, Wavre, Belgium); once at delivery, once one month after delivery and once six months after delivery. Each dose $(10 \mathrm{mcg})$ was administered intramuscularly. All infants also received a single dose of HBIg (HyperHEP B; Grifols Therapeutics Inc, Los Angeles, CA, USA) 110 IU at delivery. Infants underwent testing for $\mathrm{HBsAg}$ and anti-HB level three months after administration of the last dose of hepatitis $B$ vaccine, according to the guidelines set by the Ministry of Health, Singapore.

For the siblings of the infants, information on maternal $\mathrm{HBsAg}$ and HBeAg status prior to their delivery, as well as vaccination history, was collected from National Immunisation Registry records. The vaccine response of these children was traced from their health records, which were available from the National Electronic Health Records system. If the aforementioned information was not available, the child was excluded from the study. Siblings who were born after October 2006, and thus received $\mathrm{HBlg}$ at delivery, were included in the prospective infant group to form a cohort of children who received HBIg in addition to the hepatitis B vaccine. Siblings who were born prior to October 2006, and thus did not receive HBIg, formed the control cohort of children who only received hepatitis $B$ vaccine without HBlg. In the present study, vertical transmission was considered to have occurred if HBV was detected in the serum of the infant (or sibling), regardless of whether they were HBsAgpositive or -negative.

Statistical analysis was performed using IBM SPSS Statistics version 20.0 for Windows (IBM Corp, Armonk, NY, USA). Fisher's exact test was used to compare the categorical variables and determine if the associations were statistically significant. All tests were two-sided and a p-value $<0.05$ was considered statistically significant.

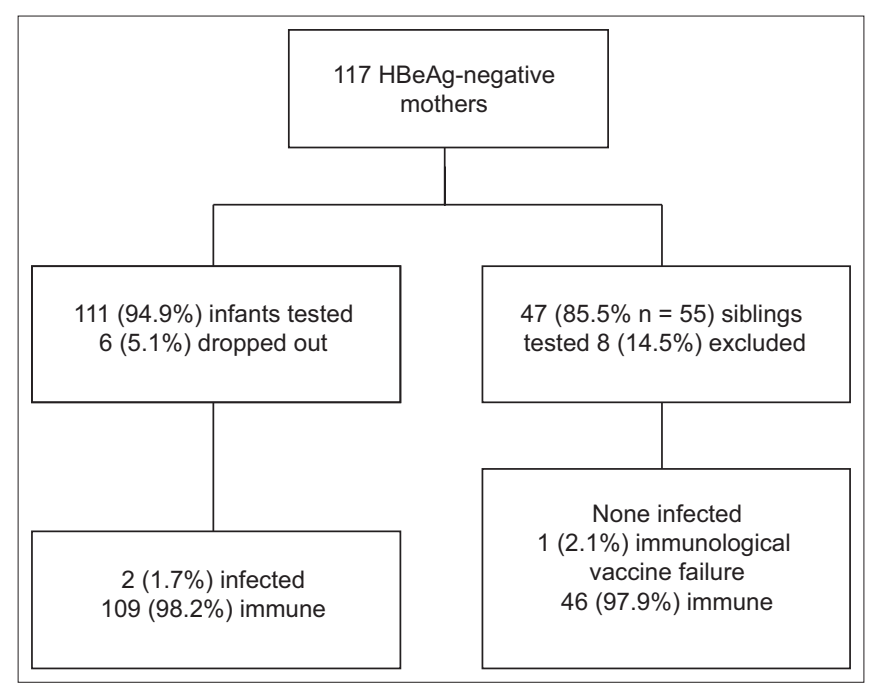

Fig. 1 Flow chart shows subject recruitment for the study. $\mathrm{HBeAg}$ : hepatitis $B$ e antigen

\section{RESULTS}

A total of $120 \mathrm{HBsAg-positive} \mathrm{and} \mathrm{HBeAg-negative} \mathrm{mothers}$ gave birth during the study period. Three mothers who were $\mathrm{HBeAg-positive} \mathrm{in} \mathrm{an} \mathrm{earlier} \mathrm{pregnancy} \mathrm{were} \mathrm{excluded} \mathrm{from} \mathrm{the}$ study. Among the remaining 117 mother-child pairs, 6 (5.1\%) defaulted on follow-up for their serological testing despite calls and reminders. Hence, serological results were available only for 111 pairs for prospective cohort analysis. The overall default rate among the infant cohort was $5.1 \%$ (Fig. 1).

A total of 55 children (i.e. older siblings of the infants delivered during the study period) from the 117 mothers were delivered before the study period. 8 (14.5\%) of these 55 siblings were excluded due to lack of consent or incomplete results. Among the remaining 47 siblings, 26 (55.3\%) were born after 2006 and received both active (hepatitis B vaccine) and passive (HBIg) immunisation; these 26 children, together with the 111 infants from the current pregnancies, formed the study group. The remaining 21 children were born in the years 2001-2006 and received only active immunisation; these siblings formed the control group.

Two infants from the study group $(\mathrm{n}=137)$ were infected via vertical transmission despite receiving $\mathrm{HBIg}$. Both of these infants had anti-HB levels $<10 \mathrm{IU} / \mathrm{L}$ and were HBsAg-negative but positive for HBV DNA; they had HBV genotype $\mathrm{C}$ that also had surface gene variants, demonstrating that the vaccine likely leads to amino acid changes in the surface antigen. One other infant had an anti-HB level $<10 \mathrm{IU} / \mathrm{L}$ and was initially found to be HBsAg-negative and negative for HBV DNA, but had a subsequent anti-HB level of $945 \mathrm{IU} / \mathrm{L}$ after three further doses of HBV vaccine.

One sibling from the study group who had received $\mathrm{HBIg}$ was found to have true immunological vaccine failure, as she was not able to demonstrate an anti-HB level $>10$ IU/L despite receiving a total of six doses of $\mathrm{HBV}$ vaccine; she did not have occult HBV virus. None of the 21 control patients who were born to HBeAg-negative mothers and did not receive HBIg were infected. 


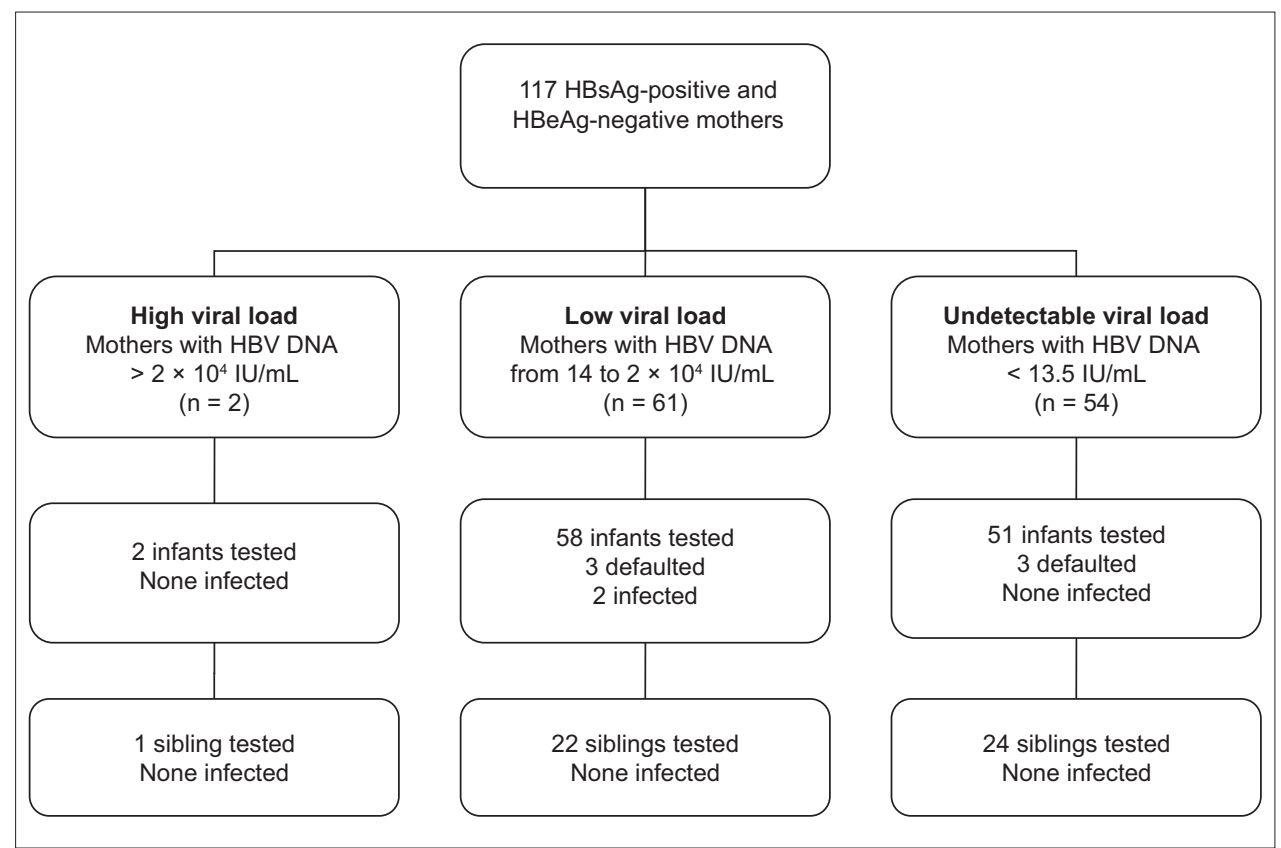

Fig. 2 Flow chart shows the recruited subjects according to maternal hepatitis B virus (HBV) DNA load (measurements were taken in 2009-2013). HBeAg: hepatitis B e antigen; HBsAg: hepatitis B surface antigen

The vertical transmission rate was $1.5 \%$ among the children who received $\mathrm{HBIg}$ (i.e. study group) and $0 \%$ among the children who did not, i.e. control group $(p=1.00)$. A total of 61 and 54 HBeAg-negative mothers had low (i.e. between $14 \mathrm{IU} / \mathrm{mL}$ and $2 \times 10^{4} \mathrm{IU} / \mathrm{mL}$ ) and undetectable (i.e. $<13.5 \mathrm{IU} / \mathrm{mL}$ ) viral loads, respectively. None of the children of the $54 \mathrm{HBeAg}$-negative mothers with undetectable viral load (Fig. 2) demonstrated vertical transmission, regardless of whether they received $\mathrm{HBIg}$ $(n=51)$ or not $(n=24)$. Two infants who received HBIg and one sibling from $2(1.7 \%) \mathrm{HBeAg}$-negative mothers with high viral load (i.e. $>2 \times 10^{4} \mathrm{IU} / \mathrm{mL}$ ) were tested; none of them had vertical transmission.

\section{DISCUSSION}

The results of the present study showed that children from $\mathrm{HBsAg-positive} \mathrm{and} \mathrm{HBeAg-negative} \mathrm{mothers} \mathrm{do} \mathrm{not} \mathrm{require} \mathrm{HBIg}$ prophylaxis. Universal hepatitis B vaccination has been practised in Singapore since 1987. As a result, the seroprevalence of HBsAg positivity among children aged 1-17 years has decreased to $0.3 \%$ in Singapore, ${ }^{(5)}$ thus achieving the WHO's Western Pacific Region goal on chronic HBV infection among children. Children of HBeAg-negative mothers born prior to 2006 only received hepatitis B vaccination without HBlg; in a study conducted in 1997, none of the children who received hepatitis B vaccine (but not $\mathrm{HBIg}$ ) were infected via vertical transmission. ${ }^{(6)}$

In the present study, the $51(43.6 \%)$ infants of mothers who were $\mathrm{HBeAg-negative} \mathrm{with} \mathrm{undetectable} \mathrm{prenatal} \mathrm{viral} \mathrm{load} \mathrm{were}$ not at risk of vertical transmission. Thus, the addition of HBIg did not confer any additional benefits. The older siblings, who were born before November 2006 and only given hepatitis B vaccine without $\mathrm{HBIg}$, were also found to be adequately protected from hepatitis B transmission. Mothers with undetectable viral load constituted about half $(46.2 \%, \mathrm{n}=54)$ of the HBeAg-negative mothers in the present study. Oon et $\mathrm{al}^{(3)}$ demonstrated that vertical transmission was not detected in close to 600 infants from $\mathrm{HBeAg-negative} \mathrm{mothers.} \mathrm{Given} \mathrm{these} \mathrm{observations,} \mathrm{the}$ role of $\mathrm{HBIg}$ in preventing vertical transmission of hepatitis $\mathrm{B}$ in full-term neonates from $\mathrm{HBsAg}$-positive and $\mathrm{HBeAg}$-negative mothers is questionable, as was highlighted in the $\mathrm{WHO}$ position paper. ${ }^{(1}$

In many Asian countries, where HBlg may not be readily available, universal vaccination with hepatitis B vaccine may still be the option of choice for HBeAg-negative mothers. There are also concerns that vaccination with HBIg may blunt long-term immunological responses in the infants ${ }^{(7,8)}$ and increase the risk of occult HBV infection. ${ }^{(9)}$ In the present study, only one sibling was found to have true immunological vaccine failure and two infants were found to have occult infection. Larger, cost-effective analyses will be needed to determine the risks and benefits of universal $\mathrm{HBlg}$ immunisation against the cost of prenatal testing for maternal viral load and giving HBIg to those who have detectable HBV DNA.

It was interesting that HBV DNA was detected in two infants who were HBsAg-negative (tested using Architect HBsAg Qualitative II; Abbott Laboratories Pte Ltd, Singapore). These surface gene mutants, which have been associated with HBIg administration, ${ }^{(9)}$ were not detected in their respective mothers. Surface gene mutants have been previously described in studies conducted in Singapore, ${ }^{(4)}$ Taiwan $^{(8,10)}$ and India. ${ }^{(9)}$ With Singapore's current adoption of the administration of universal hepatitis B vaccination and $\mathrm{HBI}$, we may see a higher prevalence of these surface mutants in the future, especially since the same recombinant vaccine that was used in the aforementioned studies (where surface gene mutants were observed) is being used in Singapore.

The present study was not without limitations. It involved a birth cohort from a single tertiary centre and thus captured the 
outcomes of about a tenth of the births in Singapore; this may not be sufficiently representative of the national cohort. In addition, the number of historical controls in the present study was small. However, as Singapore was able to reduce the carrier rate in young children to almost zero with the previous vaccination guidelines that did not require the use of $\mathrm{HBIg}^{(11)}$ the vertical transmission risk among these mothers was unlikely to be high. As six of the study subjects (in the prospective cohort) defaulted in the present study, we were unable to determine their outcomes. However, given the low historical vertical transmission infection rates, even if we assumed the worst scenario (i.e. that all six of them were infected with $\mathrm{HBV}$ ), the overall vertical infection rate would not be higher than $5.8 \%$.

To conclude, the vertical transmission rate of infants born to $\mathrm{HBs} A$ g-positive and $\mathrm{HBeAg}$-negative mothers, who were also negative for HBV DNA, is low. The administration of HBIg in addition to hepatitis $B$ vaccine to this group of infants may not have significant benefits. More research is needed to determine the risks and benefits of universal HBlg immunisation against the cost of prenatal testing for maternal viral load and selective HBIg vaccination.

\section{ACKNOWLEDGEMENTS}

The present study was supported by funding from the National Healthcare Group Small Innovative Grant. The authors thank Dr Dimple Rajgor for her assistance in reviewing, editing, formatting and submitting the manuscript for publication, as well as the families of the patients for their participation in the study. The authors would like to dedicate this article to the late Prof Kim Leong Tan (1936-2015), Ex-Chief, Department of Neonatology, National University of Singapore, Singapore, for his work in this field and inspiring his students to pursue careers in the field of research.

\section{REFERENCES}

1. World Health Organization. WHO position paper. Weekly epidemiological record [online] 2009; 84:405-20. Available at: http://www.who.int/ wer/2009/wer8440.pdf?ua=1. Accessed December 15, 2015.

2. Mast EE, Margolis HS, Fiore AE, et al; Advisory Committee on Immunization Practices (ACIP). A comprehensive immunization strategy to eliminate transmission of hepatitis B virus infection in the United States: recommendations of the Advisory Committee on Immunization Practices [ACIP] part 1: immunization of infants, children, and adolescents. MMWR Recomm Rep 2005; 54(RR-16):1-31.

3. Oon CJ, Lim GK, Ye Z, et al. Molecular epidemiology of hepatitis B virus vaccine variants in Singapore. Vaccine 1995; 13:699-702.

4. Chong-Jin O, Wei Ning C, Shiuan K, Gek Keow L. Identification of hepatitis B surface antigen variants with alterations outside the "a" determinant in immunized Singapore infants. J Infect Dis 1999; 179:259-263.

5. Ang LW, Tey SH, Cutter J, James L, Goh KT. Seroprevalence of hepatitis B virus infection among children and adolescents in Singapore, 2008-2010. J Med Virol 2013; 85:583-8.

6. Goh KT. Prevention and control of hepatitis B virus infection in Singapore. Ann Acad Med Singapore 1997; 26:671-81.

7. Yang YJ, Liu CC, Chen TJ, et al. Role of hepatitis B immunoglobulin in infants born to hepatitis B e antigen-negative carrier mothers in Taiwan. Pediatr Infect Dis J 2003; 22:584-88.

8. El Chaar M, Candotti D, Crowther RA, Allain JP. Impact of hepatitis B virus surface protein mutations on the diagnosis of occult hepatitis $B$ virus infection. Hepatology 2010; 52:1600-10.

9. Pande C, Sarin SK, Patra S, et al. Hepatitis B vaccination with or without hepatitis B immunoglobulin at birth to babies born of HBsAg-positive mothers prevents overt HBV transmission but may not prevent occult HBV infection in babies: a randomized controlled trial. J Viral Hepat 2013; 20:801-10.

10. Hsu HY, Chang MH, Ni YH, et al. Long-term follow-up of children with postnatal immunoprophylaxis failure who were infected with hepatitis B virus surface antigen gene mutant. J Infect Dis 2013; 207:1047-57.

11. Ministry of Health, Singapore. Prevention \& control of hepatitis B virus infection in Singapore. Epidemiological News Bulletin [online] 2002. Available at: https://www.moh.gov.sg/content/dam/moh_web/Statistics/ Epidemiological_News_Bulletin/2002/enb06_02w.pdf. Accessed April 20, 2015. 